\title{
Effect of fermented spent instant coffee grounds on milk productivity and blood profiles of lactating dairy cows
}

\author{
Yongjun Choi ${ }^{1}$, Jongsu Rim ${ }^{1}$, Honggu Lee ${ }^{1}$, Hyunchul Kwon ${ }^{1}$, Youngjun Na ${ }^{1}$, and Sangrak Lee ${ }^{1, *}$
}

* Corresponding Author: Sangrak Lee Tel: +82-2-450-3696, Fax: +82-2-455-1044,

E-mail: leesr@konkuk.ac.kr

1 Department of Animal Science and Technology, Konkuk University, Seoul 05029, Korea

ORCID

Yongjun Choi

https://orcid.org/0000-0002-5759-4108 Jongsu Rim

https://orcid.org/0000-0002-3868-7077

Honggu Lee

https://orcid.org/0000-0002-0679-5663

Hyunchul Kwon

https://orcid.org/0000-0003-0099-7333

Youngjun $\mathrm{Na}$

https://orcid.org/0000-0002-4643-0191

Sangrak Lee

https://orcid.org/0000-0002-8905-0770

Submitted Nov 12, 2018; Revised Jan 10, 2019; Accepted Feb 5, 2019
Objective: This study was conducted to evaluate the fermentation characteristics under low mesophilic temperature of spent instant coffee ground (SICG) and to estimate the effect of fermented SICG (FSICG) as alternative feed ingredient on milk productivity of dairy cows. Methods: In the fermentation trial, fermentation of SICG was performed to investigate changes in characteristics using the microbial mixture (Lactobacillus plantarum, Saccharomyces cerevisiae, and Bacillus subtilis $=1: 1: 1$ ) for 21 days at $20^{\circ} \mathrm{C}$ under anaerobic conditions. Molasses was added at $5 \%$ of dry mass. In the animal trial, eighteen Holstein Friesian cows were used to evaluate the nutritive value of the FSICG which was fermented for 14 days under the same condition as the fermentation trial.

Results: In the fermentation trial, the dry matter $(\mathrm{DM})$ and organic matter content linearly decreased with fermentation time ( $<<0.001$ and $p=0.008$, respectively). The acid detergent insoluble nitrogen content linearly decreased with fermentation time $(\mathrm{p}=0.037)$. The microorganism counts linearly increased for Lactobacillus plantarum, Saccharomyces cerevisiae, and Bacillus subtilis across fermentation time $(\mathrm{p}<0.001)$. In the animal trial, the DM intake of the control and FSICG treatment were not significantly different, as were milk yield, $4 \%$ fat corrected milk, fat-protein corrected milk, and feed to milk conversion content. Fat, protein, lactose, non-fat solids, milk urea nitrogen, and somatic cell counts were also not significantly different in milk composition between treatments.

Conclusion: FSICG should be considered a sufficient substitute for cottonseed as a feed component, and 5\% DM of a dietary FSICG level was appropriate for dairy cow diets.

Keywords: Spent Instant Coffee Ground; Fermentation; Milk Production; Milk Composition; Lactating Dairy Cow

\section{INTRODUCTION}

Coffee is the second most traded item in the world next to oil [1]. The increase in coffee consumption has caused an increase in waste, with approximately 10 thousand tons of spent coffee grounds (SCG) produced every year in South Korea. For this reason, the recycling of SCG is important and various studies have been conducted to better utilize the SCG such as through sugar extraction, composting, and sorbent for metal ions [2]. Furthermore, previous studies have reported that coffee grounds exhibited a useful chemical composition as a ruminant feed component $[3,4]$. However, there are some disadvantages that may limit its use as a feed component, such as low palatability and low nitrogen digestibility [5]. Therefore, enhancing the palatability and nitrogen digestibility of SCG is needed to utilize it as a feed component.

The SCG contain various antioxidants such as caffeine, melanoidin, and polyphenols [6]. Of these antioxidants, melanoidin is produced through high temperature and pressure and is known to have low nutrition and digestibility in animals [2]. In the previous study, it was 
reported that molasses wastewater including melanoidin was decolorized by Lactobacillus plantarum (L. plantarum) isolated from pickle [7]. Furthermore, fermenting spent instant coffee grounds (SICG) with $L$. plantarum showed a positive effect on protein digestibility in sheep [8]. However, few studies have been conducted on the use of SCG as an animal feed in dairy cows.

The volume of production and cost of by-products is an important factor influencing the use of SCG as a feed component. Although fermentation has a known positive effect on the function of SCG, it is a factor that increases the cost of the by-product. In a previous study, fermentation was performed under anaerobic tension and mesophilic conditions [8]. These conditions might increase the cost to produce and make it less competitive as a feed component. For this reason, a study on a cheaper fermentation method is needed in order to utilize it on the farm.

Therefore, the objective of this study was: i) to evaluate the fermentation characteristics of the SICG under low mesophilic temperatures, and; ii) to estimate the effect of fermented SICG (FSICG) as alternative feed ingredient on the milk productivity of dairy cows.

\section{MATERIALS AND METHODS}

This experiment was performed in compliance with the guidelines of the Institutional Animal Care and Use Committee at Konkuk University (Approval number: KU16139).

Spent instant coffee grounds and fermentation process The SICG used in the experiment originated from the factory of Dongsuh food industry (Incheon, Korea) and was stored at $-20^{\circ} \mathrm{C}$ until commencing the experiment. The chemical composition of SICG was determined and shown in Table 1. The SICG was sterilized using an autoclave (HB-506, HANBAEK Co., Bucheon, Korea) before lab scale fermentation.

Fermentation was performed to investigate the change in characteristic and to determine fermentation period of SICG

Table 1. Chemical composition of spent instant coffee grounds

\begin{tabular}{ll}
\hline Items & SICG \\
\hline $\mathrm{DM}(\%)$ & $46.9 \pm 0.02^{1)}$ \\
OM (\% DM) & $98.2 \pm 0.03$ \\
CP (\% DM) & $10.9 \pm 1.30$ \\
EE (\% DM) & $11.2 \pm 0.05$ \\
NDF (\% DM) & $70.6 \pm 2.53$ \\
ADF (\% DM) & $66.3 \pm 1.12$ \\
ADIN (\% DM of total N) & $68.8 \pm 2.72$ \\
\hline
\end{tabular}

SICG, spent instant coffee grounds; DM, dry matter; OM, organic matter; $C P$, crude protein; $E E$, ether extract; NDF, neutral detergent fiber; ADF, acid detergent fiber; ADIN, acid detergent insoluble nitrogen.

1) Mean \pm standard deviation. using L. plantarum (ATCC 14917), Bacillus subtilis (B. subtilis; ATCC 6633), and Saccharomyces cerevisiae (S. cerevisiae; ATCC 13007) in the lab scale. The microorganisms were cultured in a liquid medium and the number of microbes calculated from the growth curve of the solid medium after $24 \mathrm{~h}$ fermentation time using an ELISA reader (Bio-Tek, Winooski, VT, USA). The microorganisms to be inoculated were cultured in a liquid medium for $24 \mathrm{~h}$ and then prepared in a ratio of $1: 1: 1$, inoculated at $1.0 \times 10^{5} \mathrm{cfu} / \mathrm{g}$ of dry matter (DM). Fermentation of SICG was performed using a sterile plastic bag (WhirlPak, Nasco, Fort Atkinson, WI, USA, $10 \mathrm{~cm} \times 20 \mathrm{~cm}$ ) for 21 days at $20^{\circ} \mathrm{C}$ in anaerobic condition following the addition of molasses. Sampling was performed at $0,3,6,9,12,15$, and 21 days.

Based on the result of lab scale fermentation, instant coffee grounds were respectively divided into $200 \mathrm{~kg}$ portions (approximately $60.0 \% \mathrm{DM}$ ) and each placed into a separate plastic bag $(100 \mathrm{~cm} \times 100 \mathrm{~cm} \times 140 \mathrm{~cm})$. This was carried out with eight replications for utilizing as a feed ingredient in the dairy cow. The fermentation was performed by inoculating $1.0 \times 10^{5}$ cfu/g DM of the mixed inoculum (L. plantarum, B. subtilis, and S. cerevisiae $=1: 1: 1$ ) for 14 days at a moisture of $70 \%$ and temperature $20^{\circ} \mathrm{C}$ in the anaerobic condition following the addition of molasses. After mixing the inoculum, the mixture was compressed to remove air and was flushed with carbon dioxide gas in the plastic bags to make anaerobic conditions.

Fermentation quality was evaluated by chemical composition, $\mathrm{pH}$, volatile fatty acids (VFA) and ammonia nitrogen content after sampling. The $\mathrm{pH}$ was immediately estimated after sampling, the samples were stored at $-20^{\circ} \mathrm{C}$ after pretreatment for analysis of chemical composition, ammonia nitrogen, and VFA.

\section{Microorganism counts}

The sample was prepared by adding $450 \mathrm{~mL}$ distilled water containing $25 \%$ glycerine to $50 \mathrm{~g}$ FSICG and the supernatant collected after homogenization. The number of microorganisms was determined using the diluted supernatant with $10^{-2}$, $10^{-3}, 10^{-4}, 10^{-5}$, and $10^{-6}$ according to the method of standard plate count [9]. The number microorganisms were compared using a $\log _{10}$ scale.

\section{Animals and experiment design}

A total of eighteen Holstein Friesian cows (body weight: 690.0 $\pm 63.0 \mathrm{~kg}$ ) were used during the experiment. The average temperature and relative humidity during the experiment were $9.8^{\circ} \mathrm{C} \pm 4.3^{\circ} \mathrm{C}$ and $70.6 \% \pm 12.7 \%$, respectively. The average number of calves produced by experimental animals was $2.3 \pm 1.3$ year, and the number of days in milk was 194.0 013.0 days. Animals were organized according to milk yield, days in milk and parity and then allotted into six sawdust-bedded pens (three head/pen) with an individual electronic feeding gate. 
The experimental unit was an individual animal. The treatments were basal diet (control) and FSICG (experimental), with the diet formulated according to NRC guidelines [10] (Table 2). In the experimental diet, cotton seed and cotton seed pellets in the basal diet were replaced by FSICG (Table 3 ). The experiment was performed using a randomized block design for six weeks (individual electronic feeding gate adaptation period, two weeks; experimental diet adaption period, four weeks; data collection period, two weeks). Experimental feeds were fed twice a day at 0900 and $1600 \mathrm{~h}$ ad-libitum in form of total mixed ration. The residue of the previous feeding was weighed before the next feeding. The water and mineral block were available ad-libitum.

\section{Milk yield and composition}

Milk yield was automatically measured using a tandem milking system (Milking Parlor Auto Tandem, GEA Group Co., Düsseldorf, Germany) twice a day at 0500 and 1600 during the entire experimental period. The sample of milk was collected in $20 \mathrm{~mL}$ containers using the sampling port on a milking machine each week. An anticorrosive agent (Broad spectrum microtabs II, Advanced Instrument Inc., Norwood, MA, USA) was added to prevent any changes in the milk sample before being stored at $4^{\circ} \mathrm{C}$ until the analysis of the milk composition. The milk composition was evaluated using near-infrared spectrophotometer (Milko-scan FT 6000, Foss electric Co.,

Table 2. Chemical composition of fermented spent instant coffee grounds after 14 days fermentation

\begin{tabular}{lcc}
\hline Items & SICG $^{1)}$ & FSICG $^{1)}$ \\
\hline Chemical compositions & & \\
OM (\% DM) & $98.30 \pm 0.43$ & $96.91 \pm 0.08^{2)}$ \\
CP (\% DM) & $10.50 \pm 0.53$ & $11.72 \pm 0.07$ \\
NDF $(\%$ DM) & $70.33 \pm 0.33$ & $74.82 \pm 0.72$ \\
ADF $(\%$ DM) & $59.67 \pm 0.14$ & $62.87 \pm 0.09$ \\
ADIN (\% DM of total N) & $70.67 \pm 0.01$ & $66.14 \pm 0.01$ \\
Cells count $\left(\right.$ Log ${ }_{10}$ cfu/g) & & \\
Lactobacillus plantarum & $N D$ & $5.43 \pm 0.18$ \\
Saccharomyces cerevisiae & $N D$ & $5.68 \pm 0.38$ \\
Bacillus subtilis & $N D$ & $5.46 \pm 0.23$ \\
Fermentation characteristics & & \\
pH & $5.38 \pm 0.11$ & $4.54 \pm 0.07$ \\
Lactic acid $(\mu g / L)$ & $N D$ & $4.92 \pm 0.01$ \\
Acetic acid $(\mu g / L)$ & $N D$ & $1.05 \pm 0.02$ \\
Propionic acid $(\mu g / L)$ & $N D$ & $0.13 \pm 0.00$ \\
Butyric acid $(\mu g / L)$ & $N D$ & $0.00 \pm 0.33$ \\
Ammonia-N $(\mu g / m L)$ & $N D$ & $2.30 \pm 0.03$ \\
\hline
\end{tabular}

$\mathrm{OM}$, organic matter; $\mathrm{DM}$, dry matter; $\mathrm{CP}$, crude protein; NDF, neutral detergent fiber; ADF, acid detergent fiber; ADIN, acid detergent insoluble nitrogen; ND, not detected.

1) SICG (spent instant coffee ground), not fermented spent instant coffee grounds $+5 \%$ molasses; FSICG (fermented spent instant coffee ground), fermented spent instant coffee grounds $+5 \%$ molasses.

2) Mean \pm standard deviations.
Table 3. Total mixed ration formula and chemical composition of diets in fermented spent instant coffee ground feeding trial in lactating dairy cows

\begin{tabular}{|c|c|c|}
\hline Items & Control & Treatment \\
\hline \multicolumn{3}{|l|}{ Ingredient (\%) } \\
\hline Commercial mixed feed ${ }^{11}$ & 20.83 & 20.83 \\
\hline Molasses & 2.22 & 2.22 \\
\hline Corn cracked & 6.11 & 6.11 \\
\hline Corn gluten feed & 4.17 & 4.17 \\
\hline Beet pulp pellet & 1.39 & 1.39 \\
\hline Brewers grain (wet) & 9.03 & 9.03 \\
\hline Cotton seed & 6.25 & 4.86 \\
\hline Cotton seed pellet & 1.39 & - \\
\hline FSICG & - & 10.56 \\
\hline Alfalfa hay & 8.33 & 8.33 \\
\hline Oat hay & 4.17 & 4.17 \\
\hline Timothy hay & 5.56 & 5.56 \\
\hline Bermuda grass hay & 2.78 & 2.78 \\
\hline Klein grass hay & 4.86 & 4.86 \\
\hline Water & 22.92 & 15.14 \\
\hline Total & 100.00 & 100.00 \\
\hline \multicolumn{3}{|l|}{ Chemical composition } \\
\hline DM (\%) & 62.41 & 63.63 \\
\hline Forage ratio (\% DM) & 37.03 & 36.32 \\
\hline $\operatorname{TDN}(\% \mathrm{DM})^{2)}$ & 67.88 & 68.54 \\
\hline $\mathrm{CP}(\% \mathrm{DM})$ & 16.57 & 16.34 \\
\hline $\mathrm{EE}(\% \mathrm{DM})$ & 4.40 & 4.59 \\
\hline NFC (\% DM) & 29.27 & 28.48 \\
\hline CF (\% DM) & 18.49 & 18.67 \\
\hline NDF (\% DM) & 42.49 & 43.65 \\
\hline ADF (\% DM) & 25.27 & 26.62 \\
\hline $\mathrm{NE}_{\mathrm{L}}(\text { Mcal/kg DM })^{2)}$ & 1.54 & 1.56 \\
\hline
\end{tabular}

FSICG, fermented spent instant coffee grounds; DM, dry matter; TDN, total digestible nutrient; $C P$, crude protein; $E E$, ether extract; $N F C$, non-fibrous carbohydrate; NDF, neutral detergent fiber; $A D F$, acid detergent fiber; $\mathrm{NE}_{L^{\prime}}$ net energy for lactation.

1) Commercial mixed feed formula: Corn grain, 30.0\%; molasses, 5.0\%; soybean meal, $22.2 \%$; rapeseed meal, $7 \%$; corn gluten feed, $10.0 \%$; copra meal, $5.6 \%$; palm oil meal, $15.0 \%$; limestone, $2.3 \%$; salt, $0.8 \%$; sodium bicarbonate, $0.8 \%$; by-pass fat, $0.3 \%$; Vit and mineral premix, $1.0 \%$.

${ }^{2)}$ TDN and $\mathrm{NE}_{\mathrm{L}}$ was calculated by NRC 2001 model.

Hilleroed, Denmark).

\section{Chemical analysis}

All samples were dried in an oven (HB-503-LF, Hanbaek Scientific Technology, Bucheon, Korea) at $60^{\circ} \mathrm{C}$ for $48 \mathrm{~h}$ and they were ground and passed through a $1 \mathrm{~mm}$ screen with a micro hammer mill (Nr9737840, Culatti AG, Steinenberg, Switzerland). The $\mathrm{DM}$, organic matter $(\mathrm{OM})$, crude protein $(\mathrm{CP})$, and ether extract (EE) were analyzed according to AOAC method [11]. The neutral detergent fiber (NDF) and acid detergent fiber (ADF) were analyzed with ANKOM Fiber Analyzer (A200, Ankom Inc., USA) according to method of Van Soest et al [12]. The non-fiber carbohydrate content was calculated by subtraction of $\mathrm{CP}, \mathrm{NDF}, \mathrm{EE}$, and ash from 
100. Acid detergent insoluble nitrogen (ADIN) was measured for nitrogen using $\mathrm{ADF}$ residues, and the nitrogen contents were determined using a distillation unit (B-324, Buchi, Flawil, Switzerland) according to method of Licitra et al [13]. The $\mathrm{pH}$ was obtained using $\mathrm{pH}$ meter (Orion Dualster-F, Thermo Fisher Scientific, Waltham, MA, USA), and ammonia nitrogen was determined according to method of Chaney and Marbach [14]. The VFA was identified by using gas chromatography (HP 6890, Agilent Technologies, Santa Clara, CA, USA), using an Omega Wax Fused Silica Capillary column (Length, $30 \mathrm{~m} 0.3 \times 2 \mathrm{~mm} \mathrm{D}_{\mathrm{f}}, 0.25 \mu \mathrm{m}$, Sigma-Aldrich Co, St. Louis, MO, USA). Carrier gas and detector used was $\mathrm{He}$ gas and flame ionization detector, respectively.

\section{Statistical analysis}

Data were analyzed using a MIXED procedure of SAS package program (SAS Inst. Inc., Cary, NC, USA) as a randomized completely block design. The model was,

$$
\mathrm{Y}_{\mathrm{i}(\mathrm{t})}=\mu+\mathrm{B}_{\mathrm{i}}+\mathrm{T}_{\mathrm{ij}}+\mathrm{E}_{\mathrm{ij}(\mathrm{t})} \text {, }
$$

where $\mu$ is average value, $B_{i}$ is block, $T_{j}$ is treatment value and $\mathrm{E}_{\mathrm{ij}(\mathrm{t})}$ is the error value. The fixed effect feed treatment, and block was parity in procedure. Polynomial orthogonal contrasts were used to determine the fermentation effect according to time using the CONTRAST option. The crossing point of quadratic broken-line and the quadratic line was determined using NLIN code in order to determine proper fermentation time. Least squares mean between treatments were assessed using a pairwise comparison method. Statistical difference and tendency were accepted at p-value less than 0.05 and 0.10 , respectively.

\section{RESULTS}

\section{Chemical composition}

Chemical composition of SICG relative to fermentation time is shown in Table 4 . The DM content linearly decreased over fermentation time $(\mathrm{p}<0.001)$, as did the OM content $(\mathrm{p}=$
0.008). The CP content showed no significant difference with fermentation time. The NDF and ADF content quadratically $(p=0.016)$ and linearly $(p=0.045)$ increased with fermentation time, respectively. The ADIN content linearly decreased $(\mathrm{p}=0.037)$ with fermentation time.

\section{Microbial count and fermentation quality}

Microbial count and fermentation characteristics in SICG in response to fermentation time are shown in Table 5. The microorganism counts increased linearly for $L$. plantarum, S. cerevisiae, and B. subtilis with fermentation time $(\mathrm{p}<0.001)$. In fermentation quality, $\mathrm{pH}$ content quadratically decreased $(\mathrm{p}=0.026)$, lactic acid quadratically increased $(\mathrm{p}=0.022)$, acetic acid linearly increased $(\mathrm{p}=0.002)$, and butyric acid linearly increased $(\mathrm{p}<0.001)$ relative to fermentation time. However, propionic acid and ammonia nitrogen exhibited no difference during fermentation.

Dry matter intake, milk yield, and milk composition Dry matter intake (DMI), milk production and milk composition are shown in Table 6. The DMI of control and FSICGfed cows showed no significant difference between treatments. Milk yield, $4 \%$ fat corrected milk (FCM), fat-protein corrected milk (FPCM) and feed to milk conversion content were also not significantly different between treatments. In the milk composition, fat, protein, lactose, non-fat solids, milk urea nitrogen, and somatic cell counts showed no significant difference between treatments.

\section{Blood profile}

Blood profile is shown in Table 7. White blood cell (WBC) content was not significantly different between treatments. In terms of WBC composition, lymphocyte and granulocyte content were not significantly different between treatments, while the monocyte content of the control group was significantly greater than those of FSICG ( $p=0.039)$. Red blood cell, hemoglobin, and platelet content showed no significant difference between treatments.

Table 4. Changes of chemical composition in spent instant coffee grounds according to fermentation time

\begin{tabular}{|c|c|c|c|c|c|c|c|c|c|c|}
\hline \multirow{2}{*}{ Chemical compositions } & \multicolumn{7}{|c|}{ Time (d) } & \multirow{2}{*}{ SEM } & \multicolumn{2}{|c|}{ p-value ${ }^{1)}$} \\
\hline & 0 & 3 & 6 & 9 & 12 & 15 & 21 & & $\mathbf{L}$ & Q \\
\hline DM (\%) & 34.1 & 31.5 & 30.0 & 29.9 & 29.7 & 29.2 & 28.2 & 0.019 & $<0.001$ & $<0.001$ \\
\hline OM (\% DM) & 97.4 & 96.9 & 96.9 & 96.9 & 97.0 & 96.7 & 96.8 & 0.107 & 0.008 & 0.175 \\
\hline $\mathrm{CP}(\% \mathrm{DM})$ & 10.5 & 11.7 & 12.1 & 11.4 & 12.1 & 12.0 & 12.5 & 0.723 & 0.131 & 0.635 \\
\hline NDF (\% DM) & 70.3 & 73.1 & 75.3 & 74.3 & 73.6 & 73.3 & 73.0 & 0.857 & 0.240 & 0.016 \\
\hline ADF (\% DM) & 59.7 & 62.1 & 62.8 & 62.9 & 62.6 & 62.9 & 63.0 & 0.833 & 0.045 & 0.097 \\
\hline ADIN (\% DM of total N) & 84.7 & 83.3 & 81.5 & 80.8 & 79.6 & 75.3 & 68.0 & 5.224 & 0.037 & 0.500 \\
\hline
\end{tabular}

SEM, standard errors of the mean; DM, dry matter; OM, organic matter; CP, crude protein; NDF, neutral detergent fiber; ADF, acid detergent fiber; ADIN, acid detergent insoluble nitrogen.

1) $L$, linear effect; $Q$, quadratic effect. 
Table 5. Changes of microorganism counts and fermentation characteristics in spent instant coffee grounds according to fermentation periods

\begin{tabular}{|c|c|c|c|c|c|c|c|c|c|c|}
\hline \multirow{2}{*}{ Items } & \multicolumn{7}{|c|}{ Time (d) } & \multirow{2}{*}{ SEM } & \multicolumn{2}{|c|}{$p$-value ${ }^{1)}$} \\
\hline & 0 & 3 & 6 & 9 & 12 & 15 & 21 & & L & Q \\
\hline \multicolumn{11}{|l|}{ Microbial counts ( $\left.\log _{10} \mathrm{cfu} / \mathrm{g}\right)$} \\
\hline Lactobacillus plantarum & 4.58 & 4.86 & 5.68 & 5.18 & 6.07 & 5.87 & 6.79 & 0.176 & $<0.001$ & 0.993 \\
\hline Saccharomyces cerevisiae & 4.67 & 5.17 & 5.87 & 5.49 & 6.20 & 5.81 & 6.76 & 0.202 & $<0.001$ & 0.508 \\
\hline Bacillus subtilis & 4.96 & 4.96 & 5.66 & 5.26 & 5.98 & 5.62 & 6.72 & 0.188 & $<0.001$ & 0.244 \\
\hline \multicolumn{11}{|l|}{ Fermentation characteristics } \\
\hline $\mathrm{pH}$ & 5.38 & 4.43 & 4.51 & 4.58 & 4.52 & 4.77 & 4.79 & 0.071 & 0.050 & 0.026 \\
\hline Lactic acid ( $\mu \mathrm{g} / \mathrm{L})$ & 1.68 & 2.83 & 3.88 & 4.24 & 5.65 & 5.17 & 6.13 & 0.370 & $<0.001$ & 0.022 \\
\hline Acetic acid $(\mu \mathrm{g} / \mathrm{L})$ & 0.77 & 0.78 & 0.81 & 0.86 & 1.00 & 1.03 & 1.29 & 0.118 & 0.002 & 0.323 \\
\hline Propionic acid ( $\mu \mathrm{g} / \mathrm{L})$ & 0.01 & 0.01 & 0.01 & 0.26 & 0.00 & 0.00 & 0.02 & 0.070 & 0.837 & 0.130 \\
\hline Butyric acid ( $\mu \mathrm{g} / \mathrm{L})$ & 0.01 & 0.00 & 0.00 & 0.00 & 0.00 & 0.00 & 0.03 & 0.001 & $<0.001$ & $<0.001$ \\
\hline Ammonia-N ( $\mu \mathrm{g} / \mathrm{mL})$ & 1.33 & 2.67 & 3.06 & 1.56 & 1.56 & 1.72 & 2.83 & 0.987 & 0.761 & 0.751 \\
\hline
\end{tabular}

SEM, standard errors of the mean; cfu, colony forming unit

${ }^{1)} L$, linear effect; $Q$, quadratic effect.

Table 6. Dry matter intake, milk production and composition of fermented spent instant coffee ground feeding trial in lactating dairy cows

\begin{tabular}{|c|c|c|c|c|}
\hline Items & Control & FSICG & SEM & $\mathrm{p}$-value \\
\hline Dry matter intake (kg/cow/d) & 27.74 & 26.11 & 1.19 & 0.210 \\
\hline \multicolumn{5}{|l|}{ Milk production } \\
\hline $4 \% \mathrm{FCM}^{11}(\mathrm{~kg} / \mathrm{cow} / \mathrm{d})$ & 33.82 & 32.14 & 2.84 & 0.262 \\
\hline $\mathrm{FPCM}^{2)}(\mathrm{kg} / \mathrm{cow} / \mathrm{d})$ & 32.06 & 31.26 & 0.80 & 0.364 \\
\hline Feed to milk conversion (kg/kg DM) & 1.12 & 1.16 & 0.09 & 0.297 \\
\hline Protein (\%) & 3.32 & 3.20 & 0.13 & 0.157 \\
\hline Lactose (\%) & 4.65 & 4.80 & 0.10 & 0.077 \\
\hline Solid not fat (\%) & 8.65 & 8.65 & 0.15 & 0.497 \\
\hline Milk urea nitrogen (mg/dL) & 14.01 & 14.80 & 1.08 & 0.275 \\
\hline Somatic cell counts ( $10^{3}$ cells $\left./ \mathrm{mL}\right)$ & 103.44 & 59.75 & 33.28 & 0.081 \\
\hline
\end{tabular}

FSICG, fermented spent coffee ground; SEM, standard error of the means; FCM, fat corrected milk; FPCM, fat-protein corrected milk; DM, dry matter.

1) $4 \% \mathrm{FCM}$ was calculated from $4 \% \mathrm{FCM}=0.4 \times$ milk yield $+15 \times$ milk fat yield.

2) $\mathrm{FPCM}$ was calculated from $\mathrm{FPCM}=$ milk yield $\times(0.337+0.116 \times$ milk fat $[\%]+0.06 \times$ milk protein $[\%])$.

\section{DISCUSSION}

In the fermentation trial, DM content decreased both linearly and quadratically relative to the fermentation time. Meanwhile,

Table 7. Blood profiles of fermented spent instant coffee ground feeding trial in lactating dairy cows

\begin{tabular}{lcccc}
\hline Items & Control & FSICG & SEM & p-value \\
\hline White blood cell $\left(10^{3} / \mu \mathrm{L}\right)$ & 11.52 & 11.51 & 1.046 & 0.996 \\
Lymphocyte $(\%$ of $\mathrm{WBC})$ & 55.82 & 61.62 & 3.898 & 0.309 \\
Monocyte $(\%$ of $\mathrm{WBC})$ & 6.12 & 4.03 & 0.66 & 0.039 \\
Granulocyte $(\%$ of $\mathrm{WBC})$ & 38.06 & 34.37 & 3.997 & 0.523 \\
Red blood cell $\left(10^{6} / \mu \mathrm{L}\right)$ & 6.40 & 6.72 & 0.295 & 0.452 \\
Hemoglobin $(\mathrm{g} / \mathrm{dL})$ & 11.73 & 12.28 & 0.313 & 0.232 \\
Platelet $\left(10^{3} / \mathrm{LL}\right)$ & 349.22 & 415.67 & 47.846 & 0.341 \\
\hline
\end{tabular}

FSICG, fermented spent coffee ground; SEM, standard error of the means; WBC, white blood cell. the OM content decreased only linearly relative to the fermentation time. These results are likely due to decreased nutrient composition via microbial fermentation. In the SICG, it was reported to have low available nutrients [4] which including the complex melanoidin which is difficult to break down [15]. For this reason, if the fermentation time is longer, a quadratic decrease in DM and OM content might be expected by the fermentation. The NDF and ADF content increased due to fermentation which can be explained as the increase in the proportion of NDF and ADF that would occur as the DM content decreases. As a result, it is evident that the fiber source of SICG was difficult to utilize by the microorganisms. The $\mathrm{CP}$ content was not significantly different after fermentation. However, ADIN content linearly decreased with fermentation time. This suggests that nitrogen could be utilized in the melanoidin complex. Furthermore, another nitrogen source was not added during the fermentation process in this study. 
In a previous study, it was reported that the fermentation using lactic acid bacteria could improve nitrogen utilization of SICG by sheep [8].

The number of L. plantarum, S. cerevisiae, and B. subtilis linearly increased over the entire fermentation time $(\mathrm{p}<0.001)$. Although the amount measured at inoculation of $0 \mathrm{~d}$ was lower than the target amount, the fermentation process proceeded without problems due to growth of the microbes. The $\mathrm{pH}$ result was quadratically decreased by the fermentation. Generally, fermentation has been used in the feed industry to prevent spoilage by microbes. The fast drop in $\mathrm{pH}$ is useful to prevent spoilage by unidentified microorganisms and can help to reduce the loss of DM by fermentation [16]. In this study, as the level of pH in FSICG was 4.43 to 4.79 after $3 \mathrm{~d}$ fermentation, it seems that it achieved a proper $\mathrm{pH}$ level to prevent spoilage. In the previous study, it reported that acidification caused by lactic acid was insufficient to prevent the growth of spoilage microbes, and the presence of other organic acid was needed [17]. As the aerobic stability is dependent on acetic acid concentration [18], the heteroinoculation of this study seems that have a positive effect on the concentration of acetic acid. As both the lactic- and acetic acid content significantly increased in this study, it seems this could be a sufficient condition to prevent spoilage. Furthermore, the low level of butyric acid content in this study means there was not only good growth of target microorganisms but also the prevention of spoilage by microbes such as clostridium [19]. The high level of ammonia nitrogen in the fermented product has also been reported in association with clostridium fermentation [20]; however, in this study the ammonia nitrogen content was low compared with the previous study, and so not a level for concern.

The FSICG used in the animal trial was fermented for 14 days and was determined using DM, ADIN, microbial count, and lactic acid content. In the fermentation result, the crossing point between $\mathrm{DM}$ content (quadratic broken-line, $\mathrm{p}<0.001$; quadratic line, $\mathrm{p}<0.001$ ) and lactic acid content (quadratic broken-line, $\mathrm{p}=0.004$; quadratic, $\mathrm{p}<0.001$ ) was shown at 9 days (not presented in table). The crossing point of quadratic broken-line in the lactic acid bacterial count (quadratic brokenline, $\mathrm{p}=0.028$; quadratic, $\mathrm{p}<0.001$ ) was shown at 12 days (not presented in table). For these reasons, the minimum fermentation time was determined as 12 days. Furthermore, as ADIN content was shown to linearly decrease during fermentation time up to 21 days, protein availability was expected to be enhanced according to increased fermentation. However, increasing the fermentation time has the disadvantage of decreasing available nutrients [16]. In conclusion, the determined fermentation time was considered appropriate.

In the animal trial, FSICG diet did not effect the DMI. In the ad-libitum condition, although animals were included based on the consideration of milk yield, days in milk, and parties, it was considered that the daily feed intake might be not similar among animals. However, observation during the experimental period did not show any rejection of the treatment feed intake by the experimental animals. This in spite of a previous study which found adding wet coffee ground to the experimental feed resulted in the DMI being quadratically decreased in sheep [21], there was also no significant difference between SCG $0 \%$ and $10 \%$ treatments $[8,21]$. In this study, as the only $5 \%$ of cottonseed was replaced by FSICG in the feed, it was considered that have a small effect on the DMI.

All variables investigating milk production did not significantly differ between the control and FSICG treatments. Although it has no significant difference in milk yield, $4 \%$ FCM, and FPCM, the value of the control was greater than those of FSICG treatment. This seems to have been influenced by the difference in DMI. However, the result was the opposite to those of feed to milk conversion. In the previous study in sheep, it was reported that as the FSICG level increased in the experimental feed, the gain to feed ratio decreased [8]. The difference between the previous and the current experiment seems to be due to the difference of replacement feed components. In the previous study, the alfalfa and timothy forage were replaced with FSICG in the experimental feed based on gross energy, whereas it was cottonseed that was replaced by FSICG in the current study. According to the calculation of digestible energy using [22], the replaced forage source was greater than those of the FSICG in the previous study, while the replaced cottonseed in the current study was similar to that of the FSICG. There were also no significant differences between control and FSICG treatments in milk chemical composition, similar to those of milk production. It means the replacement of 5\% FSICG level in dairy feed might have little possibility of causing a negative effect on milk composition. In conclusion, cottonseed could be sufficiently be replaced by FSICG in ruminant feed.

Most of the blood profiles showed no difference between control and FSICG treatments except for monocyte content. The monocyte concentration in blood has been reported to range from $2.0 \%$ to $6.7 \%$ of WBC (Leukocytes, 4.9 to $13.3 \times$ $10^{3} / \mu \mathrm{L}$; monocyte 0.1 to $0.8 \times 10^{3} / \mu \mathrm{L}$ ) [23], and so were in the normal range in this study. Although there was a significant difference between monocyte content of controls and the FSICG treatment, it was considered to not indicate a negative effect on the dairy cows as there was no significant difference in $\mathrm{WBC}$ content and they were within a reasonable range [23, 24]. As all of blood profiles were not significantly different between control and FSICG treatments, the FSICG does not seem to have a negative effect on blood profiles in dairy cows.

As the feeding of SICG in sheep has had a significant effect on water intake and urine excretion due to caffeine [8], the feeding of FSICG could be worrisome in dairy cows. In a pre- 
vious study, fermentation using anaerobic microorganism has reported reduced caffeine concentration [25], with the highest reduction in the treatment with 5\% molasses [26]. Furthermore, fermentation using microorganisms have found that caffeine can be reduced by $40 \%$ after 9 days fermentation [25]. Fortunately, the caffeine concentration in the 5\% of FSICG feed is considered acceptable compared with previous studies because cattle are known to have high caffeine tolerance. Therefore, the fermentation could have a positive effect on the improvement of protein utilization and FSICG can be considered a substitute for cottonseed in the dairy cows as a feed component.

\section{IMPLICATIONS}

The fermentation characteristics of SICG and the effect of FSICG on milk production, composition, and blood profiles were evaluated in dairy cows. Fermentation of SICG decreased $\mathrm{DM}, \mathrm{OM}, \mathrm{ADIN}$, and $\mathrm{pH}$ content and increased microbial counts, lactic acid, and acetic acid content. While decreasing $\mathrm{OM}$ content reduced the feed energy value, decreasing ADIN may enhance nitrogen availability. The animal trials showed that 5\% DM of FSICG had no negative effect on milk production and composition. Therefore, FSICG is a satisfactory substitute for cottonseed as a feed component, and 5\% DM of dietary FSICG was appropriate for dairy cow diets.

\section{CONFLICT OF INTEREST}

We certify that there is no conflict of interest with any financial organization regarding the material discussed in the manuscript.

\section{ACKNOWLEDGMENTS}

This work was supported by Korea Institute of Planning and Evaluation for Technology in Food, Agriculture, Forestry and Fisheries (IPET) through Agri-Bio industry Technology Development Program, funded by Ministry of Agriculture, Food and Rural Affairs (MAFRA) (314010-4).

\section{REFERENCES}

1. Machado EMS, Rodriguez-Jasso RM, Teixeira JA, Mussatto SI. Growth of fungal strains on coffee industry residues with removal of polyphenolic compounds. Biochem Eng J 2012;60: 87-90. https://doi.org/10.1016/j.bej.2011.10.007

2. Campos-Vega R, Loarca-Piña G, Vergara-Castañeda HA, Oomah BD. Spent coffee grounds: A review on current research and future prospects. Trends Food Sci Technol 2015;45:2436. https://doi.org/10.1016/j.tifs.2015.04.012

3. Campbell TW, Bartley EE, Bechtle RM, Dayton AD. Coffee grounds. I. Effects of coffee grounds on ration digestibility and diuresis in cattle, on in vitro rumen fermentation, and on rat growth. J Dairy Sci 1976;59:1452-60.

4. Seo J, Jung JK, Seo S. Evaluation of nutritional and economic feed values of spent coffee grounds and Artemisia princeps residues as a ruminant feed using in vitro ruminal fermentation. Peer J 2015;3:e1343. https://doi.org/10.7717/peerj.1343

5. Givens DI, Barber WP. In vivo evaluation of spent coffee grounds as a ruminant feed. Agric Wastes 1986;18:69-72. https://doi. org/10.1016/0141-4607(86)90108-3

6. Vignoli JA, Bassoli DG, Benassi MT. Antioxidant activity, polyphenols, caffeine and melanoidins in soluble coffee: The influence of processing conditions and raw material. Food Chem 2011;124:863-8. https://doi.org/10.1016/j.foodchem. 2010.07.008

7. Tondee T, Sirianuntapiboon S. Decolorization of molasses wastewater by Lactobacillus plantarum No. PV71-1861. Bioresour Technol 2008;99:6258-65. https://doi.org/10.1016/j.biortech. 2007.12.028

8. Choi Y, Rim J, Na Y, Lee SR. Effects of dietary fermented spent coffee ground on nutrient digestibility and nitrogen utilization in sheep. Asian-Australas J Anim Sci 2018;31:363-8. https:// doi.org/10.5713/ajas.17.0654

9. Wehr HM, Frank JF, Association APH. Standard methods for the examination of dairy products. Washington, DC, USA: American Public Health Association; 2004.

10. NRC. Nutrient requirements of dairy cattle. Washington, DC, USA: National Academies Press; 2001.

11.AOAC. Official methods of analysis. 18th edition. Washington, DC, USA: AOAC International; 2005.

12. Soest PJV, Robertson JB, Lewis BA. Methods for dietary fiber, neutral detergent fiber, and nonstarch polysaccharides in relation to animal nutrition. J Dairy Sci 1991;74:3583-97. https://doi.org/10.3168/jds.S0022-0302(91)78551-2

13.Licitra G, Hernandez TM, Van Soest PJ. Standardization of procedures for nitrogen fractionation of ruminant feeds. Anim Feed Sci Technol 1996;57:347-58. https://doi.org/10.1016/03778401(95)00837-3

14. Chaney AL, Marbach EP. Modified reagents for determination of urea and ammonia. Clin Chem 1962;8:130-2.

15. Bekedam EK. Coffee brew melanoidins: structural and functional properties of brown-colored coffee compounds [Ph.D. thesis]. Wageningen, The Netherlands: Wageningen University; 2008.

16. Borreani G, Tabacco E, Schmidt RJ, Holmes BJ, Muck RE. Silage review: factors affecting dry matter and quality losses in silages. J Dairy Sci 2018;101:3952-79. https://doi.org/10.3168/ jds.2017-13837

17. Savard T, Beaulieu C, Gardner NJ, Champagne CP. Characterization of spoilage yeasts isolated from fermented vegetables and inhibition by lactic, acetic and propionic acids. Food Microbiol 2002;19:363-73. https://doi.org/10.1006/fmic.2002. 
0483

18. Danner H, Holzer M, Mayrhuber E, Braun R. Acetic acid increases stability of silage under aerobic conditions. Appl Environ Microbiol 2003;69:562-7. https://doi.org/10.1128/AEM.69.1. 562-567.2003

19. Driehuis F, Elferink SO. The impact of the quality of silage on animal health and food safety: a review. Vet Q 2000;22:2126. https://doi.org/10.1080/01652176.2000.9695061

20. Ward RT. Fermentation analysis of silage: use and interpretation. In: Tri-State Dairy Nutrition Conference; 2000. pp. 117-35.

21.Xu CC, Cai Y, Zhang JG, Ogawa M. Fermentation quality and nutritive value of a total mixed ration silage containing coffee grounds at ten or twenty percent of dry matter. J Anim Sci 2007;85:1024-9. https://doi.org/10.2527/jas.2005-628

22. Feedipedia: Instant coffee byproduct [Internet]. Feedipedia website; 2013. Available from: https://www.feedipedia.org/ node/11615/
23. Roland L, Drillich M, Iwersen M. Hematology as a diagnostic tool in bovine medicine. J Vet Diagn Invest 2014;26:592-8. https://doi.org/10.1177/1040638714546490

24. Alvarez I, Gutiérrez G, Gammella M, Martínez C, Politzki R, González C. Evaluation of total white blood cell count as a marker for proviral load of bovine leukemia virus in dairy cattle from herds with a high seroprevalence of antibodies against bovine leukemia virus. Am J Vet Res 2013;74:744-9. https://doi.org/10.2460/ajvr.74.5.744

25. Mazzafera P. Degradation of caffeine by microorganisms and potential use of decaffeinated coffee husk and pulp in animal feeding. Sci Agric 2002;59:815-21. http://dx.doi.org/10.1590/ S0103-90162002000400030

26. Porres C, Alvarez D, Calzada J. Caffeine reduction in coffee pulp through silage. Biotechnol Adv 1993;11:519-23. https:// doi.org/10.1016/0734-9750(93)90020-N 